\title{
Growth inhibitory activity of kakadu Plum extracts against the opportunistic pathogen Clostridium perfringens: New leads in the prevention and treatment of clostridial myonecrosis
}

\author{
Mitchell Henry Wright, ${ }^{1}$ Joseph Sirdaarta, ${ }^{1,2}$ Ben Matthews, ${ }^{3}$ Anthony Carlson Greene, ${ }^{1}$ Ian Edwin Cock, ${ }^{1,2^{*}}$ \\ 'School of Natural Sciences, Griffith University, Nathan Campus, 170 Kessels Rd, Nathan, Queensland 4111, AUSTRALIA. \\ 'Environmental Futures Research Institute, Griffith University, Nathan Campus, 170 Kessels Rd, Nathan, Queensland 4111, AUSTRALIA. \\ ${ }^{3}$ Smart Waters Research Centre, Griffith University, Gold Coast, AUSTRALIA.
}

\begin{abstract}
Introduction: Clostridium perfringens is the etiological agent of clostridial myonecrosis and enteritis necroticans. Infections result in exotoxin production, tissue necrosis and unless promptly treated, may result in death. Terminalia ferdinandiana (Kakadu plum) fruit has documented therapeutic properties as a general antiseptic agent. Fruit extracts have been reported to inhibit the growth of an extensive panel of pathogenic bacteria. Leaf extracts have also been shown to block the growth of several bacterial species associated with autoimmune inflammatory diseases. Methods: $T$. ferdinandiana fruit and leaf solvent extracts were investigated for growth inhibitory activity by disc diffusion assay against a clinical strain of Clostridium perfringens. Their MIC values were determined to quantify and compare their efficacies. Toxicity was determined using the Artemia franciscana nauplii bioassay. Active extracts were analysed by non-targeted HPLC-OTOF mass spectroscopy (with screening against 3 compound databases) for the identification and characterisation of individual components in the crude plant extracts. Results: Methanolic and aqueous T. ferdinandiana fruit and leaf extracts, as well as the leaf ethyl acetate extract, displayed growth inhibitory activity in the disc diffusion assay against $C$. perfringens. The leaf extracts were generally more potent growth inhibitors than the corresponding fruit extracts, although the aqueous fruit extract had substantially greater efficacy than the aqueous leaf extract. The methanolic and ethyl acetate leaf extracts were particularly potent growth inhibitors, with MIC values of 206 and $117 \mu \mathrm{g} / \mathrm{ml}$ respectively. The fruit
\end{abstract}

methanolic extract also displayed good efficacy, with an MIC of $716 \mu \mathrm{g} / \mathrm{ml}$. In contrast, the chloroform and hexane extracts of both fruit and leaf were completely devoid of growth inhibitory activity. All T. ferdinandiana extracts were either nontoxic or of low toxicity in the Artemia fransiscana bioassay. Non-biased phytochemical analysis of the methanolic and ethyl acetate leaf extracts revealed the presence of high relative levels of a diversity of galloand ellagi- tannins. Conclusion: The low toxicity of the T. ferdinandiana extracts and the potent growth inhibitory bioactivity of the leaf methanolic and ethyl acetate extracts against $C$. perfringens indicates their potential as medicinal agents in the treatment and prevention of clostridial myonecrosis and enteritis necroticans. Metabolomic profiling studies indicate that these extracts contained a diversity of tannins.

Key words: Terminalia ferdinandiana, Kakadu plum, Antioxidant, Australian medicinal plants, Antibacterial extracts, Myonecrosis, Enteritis necroticans, Gas gangrene.

Correspondence:

Dr. Ian Edwin Cock, School of Natural Sciences, Griffith University, Nathan Campus, 170 Kessels Rd, Nathan, Queensland 4111, AUSTRALIA.

Contact No.: +61 7 37357637; Fax: +61 737355282

E-mail: i.cock@griffith.edu.au

DOI: 10.5530/pj.2016.2.8

\section{INTRODUCTION}

Clostridium perfringens is an endospore-forming, gram-positive bacterium and the etiological agent of various diseases, including clostridial myonecrosis and enteritis necroticans. ${ }^{1}$ The bacterium grows strictly anaerobically (although it is aerotolerant) and is found ubiquitously in the environment as part of the natural microbial flora. It is often also present in the digestive tract of humans and other vertebrates. ${ }^{2}$ Under stresses such as harsh environmental surroundings or when deprived of necessary nutrients, $C$. perfringens can produce endospores that place it in a metabolically dormant state as a defence mechanism until conditions are once again favourable for cellular proliferation. ${ }^{3}$ The environmental robustness of the bacterium has significant clinical implications and under anoxic conditions is responsible for a wide variety of diseases, some of which are highly fatal.

Clostridial myonecrosis (or gas gangrene) is a rapidly progressive, highly lethal infection of the skeletal muscle caused by several exotoxinproducing Clostridium species. Though it is caused by a number of species within the Clostridium genus (including C. septicum, C. histolyticum or C. novyi), the predominant cause of gas gangrene is through C.perfringens, which is estimated to be the causative agent in $80-90 \%$ of all documented cases. ${ }^{4,5}$ The bacterium is reliant on anaerobic conditions and thus infection occurs primarily in deep tissues, either as a result trauma or postsurgery. ${ }^{6}$ Associated exotoxins are subsequently produced and these necrotize the surrounding tissue, resulting in muscular degradation. Unless prompt treatment is administered, later symptoms may include acute renal failure, shock, coma and ultimately death.?

Current strategies in the treatment of $C$. perfringens induced gas gangrene involve a combination of both antibiotic therapy and aggressive surgical debridement. ${ }^{7}$ Without prompt treatment, gas gangrene is highly fatal and thus the removal of necrotized tissues is often necessary to reduce the chance of host death. In recent times there has been an emphasis on producing an effective vaccine, however this is viewed more as a preventative measure than as a curative therapy and thus has no use once infection has initiated. ${ }^{8}$ Furthermore, the sporadic, opportunistic nature of the pathogen results in difficulty in predicting who should receive the vaccination. Thus, the primary method of treatment currently involves the administration of a combination of penicillin and clindamycin as soon as the infection is detected. ${ }^{4}$ Although the bacterium has remained relatively susceptible to antibiotics, reports of antibiotic resistant C. perfringens have emerged and thus there is an ever-increasing need to discover and develop alternative chemotherapeutic options for the treatment of gas gangrene. ${ }^{9}$

Terminalia ferdinandiana (commonly known as Kakadu plum, gubinge, billy goat plum) is an endemic Australian plant which is noted for its extremely high antioxidant content. ${ }^{10-1}$ Indeed, T. ferdinandiana fruit 
reportedly has the highest ascorbic acid levels of any plant in the world, with levels reported as high as $6 \%$ of the recorded wet weight. This is approximately 900 times higher (g/g) than the ascorbic acid content in blueberries. T. ferdinandiana has previously been shown to have strong antibacterial activity against an extensive panel of bacteria. ${ }^{12-5}$ Solvent extracts of various polarities were tested against both gram-positive and gram-negative bacterial species. The polar extracts proved to be more effective antibacterial agents, indicating that the antibacterial components were polar. Indeed, the polar extracts inhibited the growth of nearly every bacteria tested. Both gram-positive and gram-negative bacterial species were susceptible, indicating that the inhibitory compounds may readily cross the gram-negative cell wall.

Whilst most recent interest in T. ferdinandiana has focussed on the fruit due to its high antioxidant capacity, there is a relative lack of evidence of its use as a therapeutic agent. Instead, it was considered by the first Australians to have greater worth as a highly nutritious food and as a tonic for general well-being. Greater emphasis has been traditionally given to the leaf, bark and sap/kinos, especially as an antiseptic agent. ${ }^{16-7}$ Despite their traditional therapeutic usage, these other parts of T. ferdinandiana have been less well studied. Recently, T. ferdinandiana leaf extracts were shown to have potent inhibitory activity against the bacterial triggers of several auto immune inflammatory diseases including multiple sclerosis. ${ }^{18}$ That study indicated that the inhibition of the bacterial triggers of multiple sclerosis by the leaf extracts may be due to their high tannin content. Furthermore, despite the reported broad spectrum growth inhibitory activity of $T$. ferdinandiana fruit, numerous pathogens are yet to be evaluated for the ability to inhibit their growth. The antibacterial properties of leaf extracts of this species remain largely unreported. The current study was undertaken to test the ability of T. ferdinandiana fruit and leaf extracts to inhibit the growth of the gram-positive anaerobic bacterium Clostridium perfringens and to further evaluate the phytochemical compositions of the extracts with the most potent growth inhibitory activity.

\section{MATERIALS AND METHODS}

\section{Plant source and extraction}

T. ferdinandiana fruit leaves and pulp were supplied and verified by David Boehme of Wild Harvest, Northern Territory (Australia). The pulp was frozen prior to transport and kept at $-10^{\circ} \mathrm{C}$ until processed. A voucher specimen of the pulp (KP2014GD) is maintained at School of Natural Sciences, Griffith University. The leaves were extensively dehydrated in a Sunbeam food dehydrator and the desiccated material was stored at $-30^{\circ} \mathrm{C}$. A voucher specimen (KP2015LA) is stored at the School of Natural Sciences, Griffith University. The plant materials were thoroughly dried and ground into a coarse powder prior to use. A mass of $1 \mathrm{~g}$ of ground powder was extensively extracted in $50 \mathrm{~mL}$ of either deionised water, methanol, chloroform, hexane or ethyl acetate for $24 \mathrm{~h}$ at $4^{\circ} \mathrm{C}$ with gentle shaking. All solvents were supplied by Ajax, Australia (AR grade). The extracts were filtered through filter paper (Whatman No. 54) and air dried at room temperature. The aqueous extract was lyophilised by rotary evaporation in an Eppendorf concentrator 5301. The resultant pellets were dissolved in $10 \mathrm{~mL}$ deionised water (containing $0.5 \% \mathrm{DMSO}$ ). The extract was passed through a $0.22 \mu \mathrm{m}$ filter (Sarstedt) and stored at $4^{\circ} \mathrm{C}$ until used.

\section{Qualitative phytochemical studies}

Phytochemical analysis of the extracts for the presence of triterpenoids, tannins, saponins, phytosteroids, phenolic compounds, flavonoids, cardiac glycosides, anthraquinones and alkaloids were conducted by previously described assays. ${ }^{19-21}$

\section{Antioxidant capacity}

The antioxidant capacity of each sample was assessed using a modified DPPH free radical scavenging method. ${ }^{18,22}$ Ascorbic acid (0-25 $\mu$ g per well) was used as a reference and the absorbances were measured and recorded at $515 \mathrm{~nm}$. All tests were completed alongside controls on each plate and all were performed in triplicate. The antioxidant capacity based on DPPH free radical scavenging ability was determined for each extract and expressed as $\mu \mathrm{g}$ ascorbic acid equivalents per gram of original plant material extracted.

\section{Antibacterial screening Clinical Clostridium perfringens screening}

A clinical strain of Clostridium perfringens was supplied by Ms. Jane Gifkins (Griffith University) and was originally isolated and verified by Dr. John Bates (Department of Queensland Health). Cultures were grown and maintained using a thioglycollate liquid media (Oxoid Ltd., Australia). All growth studies were performed using nutrient agar (Oxoid Ltd., Australia) under induced anaerobic conditions through the use of anaerobic jars and AnaeroGen ${ }^{\text {rx }} 3.5 \mathrm{~L}$ atmospheric generation systems (Thermo Scientific). Incubation was at $30^{\circ} \mathrm{C}$ and the stock culture was subcultured and maintained in thioglycollate liquid media at $4^{\circ} \mathrm{C}$.

\section{Evaluation of antimicrobial activity}

Antimicrobial activity of all plant extracts was determined using a modified disc diffusion assay. ${ }^{23-4}$ Briefly, $100 \mu \mathrm{L}$ of $C$. perfringens was grown in $10 \mathrm{~mL}$ of fresh thioglycollate media until they reached a count of $\sim 10^{8}$ cells $/ \mathrm{mL}$. A volume of $100 \mu \mathrm{L}$ of the bacterial suspension was spread onto nutrient agar plates and extracts were tested for antibacterial activity using $6 \mathrm{~mm}$ sterilised filter paper discs. Discs were impregnated with $10 \mu \mathrm{L}$ of $T$. fernandiana extracts, allowed to dry and placed onto the inoculated plates. The plates were allowed to stand at $4^{\circ} \mathrm{C}$ for $2 \mathrm{~h}$ before incubation at $30^{\circ} \mathrm{C}$ for $24 \mathrm{~h}$. The diameters of the inhibition zones were measured to the closest whole millimetre. Each assay was performed in at least triplicate. Mean values $( \pm$ SEM) are reported in this study. Standard discs of penicillin $(2 \mu \mathrm{g})$ and ampicillin $(10 \mu \mathrm{g})$ were obtained from Oxoid Ltd., Australia and used as positive controls to compare antibacterial activity. Filter discs impregnated with $10 \mu \mathrm{L}$ of distilled water were used as a negative control.

\section{Minimum inhibitory concentration (MIC) determination}

The minimum inhibitory concentrations (MIC) of the extracts was determined as previously described. ${ }^{25-7}$ Briefly, the plant extracts were diluted in deionised water and tested across a range of concentrations. Discs were impregnated with $10 \mu \mathrm{L}$ of the extract dilutions, allowed to dry and placed onto inoculated plates. The assay was performed as outlined above and graphs of the zone of inhibition versus concentration were plotted. Linear regression was used to determine MIC values.

\section{Toxicity screening Reference toxin for toxicity screening}

Potassium dichromate $\left(\mathrm{K}_{2} \mathrm{Cr}_{2} \mathrm{O}_{7}\right)$ (AR grade, Chem-Supply, Australia) was prepared in distilled water $(4 \mathrm{mg} / \mathrm{mL})$ and serially diluted in artificial seawater for use in the Artemia franciscana nauplii bioassay.

\section{Artemia franciscana nauplii toxicity screening}

Toxicity was tested using a modified Artermia franciscana nauplii lethality assay. ${ }^{28-30}$ Briefly, $400 \mu \mathrm{L}$ of seawater containing $\sim 43$ (mean $43.2, \mathrm{n}=155$, SD 14.5) A. franciscana nauplii were added to wells of a 48 well plate and immediately used in the bioassay. Volumes of $400 \mu \mathrm{L}$ of reference toxin 
or the diluted plant extracts were transferred to the wells and incubated at $25 \pm 1^{\circ} \mathrm{C}$ under artificial light (1000 Lux). A negative control $(400 \mu \mathrm{L}$ seawater) was run in triplicate for each plate. All treatments were performed in at least triplicate. The wells were checked at regular intervals and the number of dead counted. The nauplii were deemed dead if no movement of the appendages was detected within 10 seconds. After $24 \mathrm{~h}$, all nauplii were sacrificed and counted to determine the total \% mortality per well. The $\mathrm{LC}_{50}$ with $95 \%$ confidence limits for each treatment was calculated using probit analysis.

\section{Non-targeted HPLC-MS QTOF analysis}

Chromatographic separations were performed as previously described. ${ }^{14,31}$ Briefly, $2 \mu \mathrm{L}$ of sample was injected onto an Agilent $1290 \mathrm{HPLC}$ system fitted with a Zorbax Eclipse plus C18 column $(2.1 \times 100 \mathrm{~mm}, 1.8 \mu \mathrm{m}$ particle size). The mobile phases consisted of (A) ultrapure water and (B) $95: 5$ acetonitrile/water at a flow rate of $0.7 \mathrm{~mL} / \mathrm{min}$. Both mobile phases were modified with $0.1 \%(\mathrm{v} / \mathrm{v})$ glacial acetic acid for mass spectrometry analysis in positive mode and with $5 \mathrm{mM}$ ammonium acetate for analysis in negative mode. The chromatographic conditions utilised for the study consisted of the first 5 min run isocratically at $5 \% \mathrm{~B}$, a gradient of (B) from $5 \%$ to $100 \%$ was applied from $5 \mathrm{~min}$ to $30 \mathrm{~min}$, followed by 3 min isocratically at $100 \%$. Mass spectrometry analysis was performed on an Agilent 6530 quadrapole time-of-flight spectrometer fitted with a Jetstream electrospray ionisation source in both positive and negative mode.

Data was analysed using the Masshunter Qualitative analysis software package (Agilent Technologies). Blanks using each of the solvent extraction systems were analysed using the Find by Molecular Feature algorithm in the software package to generate a compound list of molecules with abundances greater than 10,000 counts. This was then used as an exclusion list to eliminate background contaminant compounds from the analysis of the extracts. Each extract was then analysed using the same parameters using the Find by Molecular Feature function to generate a putative list of compounds in the extracts. Compound lists were then screened against three accurate mass databases; a database of known plant compounds of therapeutic importance generated specifically for this study (800 compounds); the Metlin metabolomics database (24,768 compounds); and the Forensic Toxicology Database by Agilent Technologies (7,509 compounds). Empirical formula for unidentified compounds was determined using the Find Formula function in the software package

\section{Statistical analysis}

Data is expressed as the mean \pm SEM of at least three independent experiments.

\section{RESULTS}

\section{Liquid extraction yields and qualitative phytochemical screening}

Kakadu plum plant extractions ( $1 \mathrm{~g}$ ) with various solvents yielded dried plant extracts ranging from $18 \mathrm{mg}$ to $483 \mathrm{mg}$ (fruit extracts) and $58 \mathrm{mg}$ to $471 \mathrm{mg}$ (leaf extracts) (Table 1). Aqueous and methanolic extracts provided significantly greater yields of extracted material relative to the chloroform, ethyl acetate and hexane counterparts, which gave low to moderate yields. The dried extracts were resuspended in $10 \mathrm{~mL}$ of deionised water (containing $1 \%$ DMSO), resulting in the concentrations presented in Table 1.

\section{Antioxidant content}

Antioxidant capacity for the plant extracts (Table 1) ranged from $0.4 \mathrm{mg}$ (hexane leaf extract) to a high of $660 \mathrm{mg}$ ascorbic acid equivalence per gram of dried plant material extracted (methanolic fruit extract). The aqueous and methanolic extracts generally had higher antioxidant capacities than the corresponding chloroform, hexane and ethyl acetate extracts.

\section{Antimicrobial activity}

To determine the ability of the fruit and leaf crude extracts to inhibit C. perfringens growth, $10 \mu \mathrm{L}$ of each extract were screened using a disc diffusion assay. Bacterial growth was strongly inhibited by 5 of the 10 extracts screened (50\%) (Figure 1). The methanolic leaf extract was the most potent inhibitor of growth (as judged by zone of inhibition), with inhibition zones of $16 \pm 0.6 \mathrm{~mm}$. This compares favourably with the penicillin $(2 \mu \mathrm{g})$ and ampicillin controls $(10 \mu \mathrm{g})$, with the zones of inhibition of $12.3 \pm 0.3$ and $13 \pm 1.0 \mathrm{~mm}$ respectively. The methanolic fruit extract as well as both the aqueous and ethyl acetate leaf extracts also displayed good inhibition of $C$. perfringens growth, with $\geq 9 \mathrm{~mm}$ zones of inhibition. Typically, the leaf extracts were more potent inhibitors of $C$. perfringens growth than were their corresponding fruit extract counterparts.

The antimicrobial efficacy was further quantified through the determination of MIC values against the Kakadu plum extracts (Table 2). The aqueous and methanolic extracts (both fruit and leaf), as well as the leaf ethyl acetate extract, were effective at inhibiting C. perfringens growth, with $\mathrm{MIC}$ values generally $<1000 \mu \mathrm{g} / \mathrm{ml}(<10 \mu \mathrm{g}$ impregnated in the disc). The methanolic and ethyl acetate leaf extracts were particularly potent, with MIC values of $206 \mu \mathrm{g} / \mathrm{mL}$ (approximately $2.1 \mu \mathrm{g}$ infused into the disc) and $117 \mu \mathrm{g} / \mathrm{mL}$ (approximately $1.2 \mu \mathrm{g}$ infused into the disc) respectively. These results compare well with the growth inhibitory activity of the penicillin and ampicillin controls which were tested at $2 \mu \mathrm{g}$ and $10 \mu \mathrm{g}$ respectively. The methanolic fruit extract was also a potent C. perfringens growth inhibitor (MIC value of $716 \mu \mathrm{g} / \mathrm{ml}$ ). Whilst less potent, the aqueous fruit extract also displayed good growth inhibitory activity (MIC values of $1192 \mu \mathrm{g} / \mathrm{ml}$ ). In contrast, both chloroform and hexane extracts, as well as the fruit ethyl acetate extract, were not active, or were of only low efficacy in the assay.

\section{Quantification of toxicity}

All extracts were initially screened in the assay at $2000 \mu \mathrm{g} / \mathrm{mL}$ (Figure 2). As a reference toxin, potassium dichromate was also tested in the bioassay. The potassium dichromate reference toxin was rapid in its onset of mortality, inducing nauplii death within the first $3 \mathrm{~h}$ of exposure and $100 \%$ mortality evident within $4-5 \mathrm{~h}$ (results omitted). All aqueous and methanolic extracts as well as the ethyl acetate leaf extract showed $>90 \%$ mortality rates at $24 \mathrm{~h}$. The other extracts showed $<10 \%$ mortality rates at $24 \mathrm{~h}$, with the exception of the chloroform leaf extract.

To further quantify the effects of toxin concentration on the initiation of mortality, the extracts were serially diluted in artificial seawater to test across a series of concentrations in the Artemia nauplii bioassay at 24 hours. The $\mathrm{LC}_{50}$ values of the Kakadu plum extracts towards A. franciscana are presented in Table 2 . No $\mathrm{LC}_{50}$ values are reported in either of the hexane or chloroform extracts, nor for the ethyl acetate fruit extract, as $<50 \%$ mortality was seen in all tested concentrations. Extracts with an $\mathrm{LC}_{50}$ greater than $1000 \mu \mathrm{g} / \mathrm{ml}$ towards Artemia nauplii have been defined as being nontoxic in this assay. ${ }^{32}$ As only the ethyl acetate fruit extract had an $\mathrm{LC}_{50}$ value of $<1000 \mu \mathrm{g} / \mathrm{ml}$, all other extracts were considered nontoxic. Whilst the $\mathrm{LC}_{50}$ value for the ethyl acetate leaf extract is $<1000$ $\mu \mathrm{g} / \mathrm{ml}$, a value of $767 \mu \mathrm{g} / \mathrm{ml}$ indicates low to moderate toxicity.

\section{HPLC-MS QTOF analysis}

As the methanolic and ethyl acetate leaf extracts had the greatest antibacterial efficacy (as determined by MIC), they were deemed the 
Table 1: The mass of dried extracted material, the concentration after resuspension in deionised water, qualitative phytochemical screenings and antioxidant capacities of the Kakadu plum extracts

\begin{tabular}{|c|c|c|c|c|c|c|c|c|c|c|c|c|c|c|c|c|}
\hline 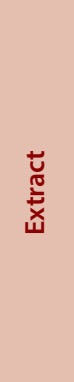 & 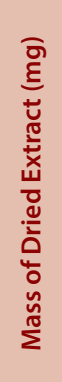 & 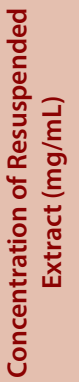 & 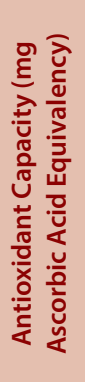 & 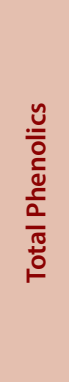 & 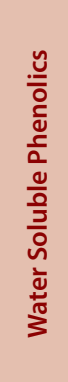 & 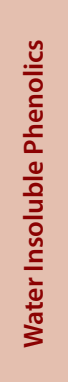 & 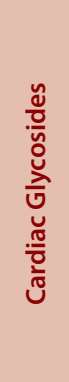 & 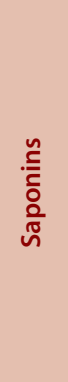 & 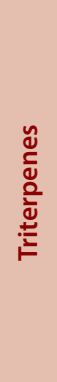 & 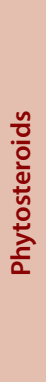 & 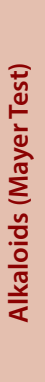 & 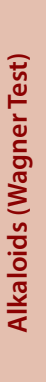 & $\begin{array}{l}\frac{n}{0} \\
\frac{0}{0} \\
\frac{0}{0} \\
\frac{\pi}{4}\end{array}$ & 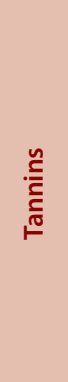 & 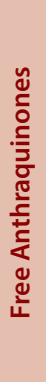 & 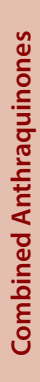 \\
\hline KFW & 483 & 48.3 & 264 & +++ & +++ & +++ & - & + & - & - & - & - & +++ & ++ & - & - \\
\hline KFM & 359 & 35.9 & 660 & +++ & +++ & +++ & - & ++ & + & - & + & + & +++ & ++ & - & - \\
\hline KFC & 62 & 6.2 & 7 & + & - & - & - & - & - & - & - & - & - & - & - & - \\
\hline KFH & 18 & 1.8 & 1 & - & - & - & - & - & - & - & - & - & - & - & - & - \\
\hline KFE & 30 & 3 & 39 & ++ & ++ & + & - & + & ++ & - & - & - & ++ & - & - & - \\
\hline KLW & 471 & 47.1 & 340 & +++ & +++ & +++ & ++ & +++ & ++ & - & - & - & ++ & +++ & + & + \\
\hline KLM & 331 & 33.1 & 150 & +++ & +++ & +++ & +++ & ++ & + & - & + & + & ++ & +++ & + & + \\
\hline KLC & 59 & 5.9 & 5 & + & - & - & - & - & - & - & - & - & - & - & - & - \\
\hline KLH & 58 & 5.8 & 0.4 & + & - & - & - & - & - & - & - & - & ++ & + & - & - \\
\hline KLE & 59 & 5.9 & 22 & +++ & +++ & +++ & - & - & - & - & - & - & ++ & ++ & - & - \\
\hline
\end{tabular}

+++ indicates a large response; ++ indicates a moderate response; + indicates a minor response; - indicates no response in the assay. KFW=aqueous Kakadu plum fruit extract; KFM=methanolic Kakadu plum fruit extract; KFC=chloroform Kakadu plum fruit extract; KFH=hexane Kakadu plum fruit extract; KFE=ethyl acetate Kakadu plum fruit extract; KLW=aqueous Kakadu plum leaf extract; KLM=methanolic Kakadu plum leaf extract; $\mathrm{KLC}=$ chloroform Kakadu plum leaf extract; KLH=hexane Kakadu plum leaf extract; KLE=ethyl acetate Kakadu plum leaf extract. Antioxidant capacity was determined by DPPH reduction and is expressed as $\mathrm{mg}$ ascorbic acid equivalence per g plant material extracted.

\begin{tabular}{|c|c|c|}
\hline Extract & MIC & $\mathrm{LC}_{50}$ \\
\hline aqueous fruit extract & 1192 & 2,080 \\
\hline methanolic fruit extract & 716 & 2,115 \\
\hline chloroform fruit extract & - & - \\
\hline hexane fruit extract & - & - \\
\hline ethyl acetate fruit extract & - & - \\
\hline aqueous leaf extract & 3125 & 1,330 \\
\hline methanolic leaf extract & 206 & 1,133 \\
\hline chloroform leaf extract & - & - \\
\hline hexane leaf extract & - & - \\
\hline ethyl acetate leaf extract & 117 & 767 \\
\hline
\end{tabular}

Numbers indicate the mean MIC and $\mathrm{LC}_{50}$ values of triplicate determinations. indicates no inhibition.

most promising extracts for further phytochemical analysis. Optimised HPLC-MS QTOF parameters used previously for the analysis of T. ferdinandiana leaf extracts ${ }^{21}$ were also used for the determination of the methanolic and ethyl acetate leaf extract compound profiles. The total compound chromatograms of the methanolic and ethyl acetate extracts are presented in Figure 3 and 4 respectively.

The T. ferdinandiana methanolic extract positive (Figure 3a) and negative ion (Figure $3 \mathrm{~b}$ ) total compound chromatogram chromatograms revealed multiple overlapping peaks in the early stages of the chromatogram corresponding to the elution of polar compounds. Most of the extract compounds had eluted within 12 minutes of the chromatogram (corresponding to approximately $32 \%$ acetonitrile). However, several prominent peaks between 12 and $16 \mathrm{~min}$ in both chromatograms, and between
24 and 30 minutes (51-66\% acetonitrile) indicates the broad spread of polarities of the compounds in this extract. The leaf ethyl acetate positive ion (Figure 4a) chromatogram had a similar elution profile to the corresponding methanolic extract, albeit with fewer peaks evident. Many of the peaks in this chromatogram corresponded to peaks at similar elution volumes in the methanolic extract, indicating that many compounds were extracted by both solvents. In contrast, much fewer peaks were evident in the leaf ethyl acetate negative ion chromatogram (Figure $4 \mathrm{~b}$ ). However, this chromatogram had significant background absorbance levels than the positive ion chromatogram due to ionisation of negative ions in this mode, possibly masking the signals for some peaks.

In total, 54 unique mass signals were noted for the T. ferdinandiana leaf methanolic and/or ethyl acetate extracts (Table 3). All of the 54 unique 
Table 3: Qualitative HPLC-MS/MS analysis of the T. ferdinandiana leaf methanolic and ethyl acetate extracts, elucidation of empirical formulas and putative identification of the compound

\begin{tabular}{|c|c|c|c|c|c|}
\hline Name & Formula & Mass & RT & KLM & KLE \\
\hline Chebulic acid (isomer 1) & $\mathrm{C}_{14} \mathrm{H}_{12} \mathrm{O}_{11}$ & 356.0395 & 0.363 & - & $+/-$ \\
\hline Shikimic acid & $\mathrm{C}_{7} \mathrm{H}_{10} \mathrm{O}_{5}$ & 174.0542 & 0.403 & - & - \\
\hline Theophylline & $\mathrm{C}_{7} \mathrm{H}_{8} \mathrm{~N}_{4} \mathrm{O}_{2}$ & 180.0649 & 0.424 & - & - \\
\hline (1S,5R)-4-Oxo-6,8-dioxabicyclo[3.2.1]oct-2-ene-2-carboxylic acid & $\mathrm{C}_{7} \mathrm{H}_{6} \mathrm{O}_{5}$ & 170.0221 & 0.484 & - & \\
\hline Mannitol & $\mathrm{C}_{6} \mathrm{H}_{14} \mathrm{O}_{6}$ & 182.0793 & 0.505 & & + \\
\hline Diprophylline & $\mathrm{C}_{10} \mathrm{H}_{14} \mathrm{~N}_{4} \mathrm{O}_{4}$ & 254.1012 & 0.512 & & + \\
\hline Protocatechuic acid & $\mathrm{C}_{7} \mathrm{H}_{6} \mathrm{O}_{4}$ & 154.0272 & 0.522 & & - \\
\hline Propionylglycine methyl ester & $\mathrm{C}_{6} \mathrm{H}_{11} \mathrm{NO}_{3}$ & 145.0744 & 0.529 & + & \\
\hline Naphtho[2",3":4',5']imidazo[2',1':2,3][1,3] thiazolo[4,5-b]quinoxaline & $\mathrm{C}_{19}^{6} \mathrm{H}_{10} \mathrm{~N}_{4} \mathrm{~S}$ & 326.0645 & 0.621 & - & \\
\hline Vanilpyruvic acid & $\mathrm{C}_{10} \mathrm{H}_{10} \mathrm{O}_{5}$ & 210.0529 & 0.632 & & - \\
\hline Valdipromide & $\mathrm{C}_{11} \mathrm{H}_{23} \mathrm{NO}$ & 185.1785 & 0.91 & & + \\
\hline Ellagic acid dihydrate & $\mathrm{C}_{14} \mathrm{H}_{10} \mathrm{O}_{10}$ & 338.0285 & 1.067 & $+/-$ & + \\
\hline Punicalagin & $\mathrm{C}_{48} \mathrm{H}_{28} \mathrm{O}_{30}$ & 1084.065 & 1.157 & - & \\
\hline Chebulic acid (isomer 2) & $\mathrm{C}_{14} \mathrm{H}_{12} \mathrm{O}_{11}$ & 356.0388 & 1.533 & $+/-$ & + \\
\hline Phloroglucinol & $\mathrm{C}_{6} \mathrm{H}_{6} \mathrm{O}_{3}$ & 126.0322 & 1.605 & + & \\
\hline Phosphoribosylaminoimidazolesuccinocarboxamide (SAICAR) & $\mathrm{C}_{13} \mathrm{H}_{19} \mathrm{~N}_{4} \mathrm{O}_{12} \mathrm{P}$ & 454.0751 & 2.489 & - & \\
\hline 2-Cyclohexylpiperidine oxalate & $\mathrm{C}_{13} \mathrm{H}_{23} \mathrm{~N} \mathrm{O}_{4}$ & 257.163 & 3.268 & & + \\
\hline (2-Methyl-4-oxo-4H-pyran-3-yloxy)-acetic acid & $\mathrm{C}_{8} \mathrm{H}_{8} \mathrm{O}_{5}$ & 184.0377 & 3.745 & - & \\
\hline Ellagic acid & $\mathrm{C}_{14}^{\circ} \mathrm{H}_{6} \mathrm{O}_{8}$ & 302.0073 & 4.372 & $+1-$ & + \\
\hline (2-Methyl-4-oxo-4H-pyran-3-yloxy)-acetic acid & $\mathrm{C}_{8} \mathrm{H}_{8} \mathrm{O}_{5}^{8}$ & 184.0374 & 4.788 & & \\
\hline 1a,25-Dihydroxy-26,27-dimethyl-22,22,23,23-tetradehydrovitamin D3 & $\mathrm{C}_{29}^{0} \mathrm{H}_{44}^{0} \mathrm{O}_{3}$ & 440.3262 & 6.929 & & + \\
\hline Chebulagic acid (isomer 1) & $\mathrm{C}_{41}^{29} \mathrm{H}_{30} \mathrm{O}_{27}$ & 954.0979 & 7.629 & - & - \\
\hline Castalagin (isomer 1) & $\mathrm{C}_{41} \mathrm{H}_{26} \mathrm{O}_{26}$ & 934.0719 & 7.671 & - & - \\
\hline Corilagin & $\mathrm{C}_{27} \mathrm{H}_{22} \mathrm{O}_{18}^{20}$ & 634.0815 & 7.773 & $+/-$ & $+/-$ \\
\hline 8-Epiiridotrial glucoside & $\mathrm{C}_{16} \mathrm{H}_{24} \mathrm{O}_{8}$ & 344.1475 & 8.42 & - & \\
\hline Punicalin & $\mathrm{C}_{34} \mathrm{H}_{22}^{24} \mathrm{O}_{22}^{8}$ & 782.0619 & 8.498 & + & + \\
\hline Chebulinic acid (isomer 1) & $\mathrm{C}_{41}^{34} \mathrm{H}_{32} \mathrm{O}_{27}$ & 956.1131 & 8.602 & - & - \\
\hline Luteolin (isomer 1) & $\mathrm{C}_{21}^{41} \mathrm{H}_{20}^{32} \mathrm{O}_{11}^{27}$ & 448.1018 & 8.726 & $+/-$ & $+/-$ \\
\hline Castalagin (isomer 2) & $\mathrm{C}_{41}^{21} \mathrm{H}_{26}^{20} \mathrm{O}_{26}$ & 934.0705 & 8.767 & - & - \\
\hline Vitexin & $\mathrm{C}_{21}^{41} \mathrm{H}_{20}^{20} \mathrm{O}_{10}$ & 432.1067 & 9.201 & $+1-$ & $+/-$ \\
\hline Exifone & $\mathrm{C}_{13} \mathrm{H}_{10} \mathrm{O}_{7}$ & 278.0431 & 9.314 & $+1-$ & $+/-$ \\
\hline Rutin & $\mathrm{C}_{27} \mathrm{H}_{30} \mathrm{O}_{16}$ & 610.1542 & 9.34 & - & \\
\hline Punicalin & $\mathrm{C}_{34} \mathrm{H}_{22} \mathrm{O}_{22}$ & 782.0619 & 9.368 & + & + \\
\hline Luteolin (isomer 2) & $\mathrm{C}_{21} \mathrm{H}_{20} \mathrm{O}_{11}$ & 448.1011 & 9.779 & $+/-$ & $+1-$ \\
\hline Chebulagic acid (isomer 2) & $\mathrm{C}_{41} \mathrm{H}_{30} \mathrm{O}_{27}$ & 954.0978 & 9.847 & - & - \\
\hline Casuarenin & $\mathrm{C}_{41}^{41} \mathrm{H}_{28} \mathrm{O}_{26}$ & 936.0868 & 9.852 & - & - \\
\hline Norstictic acid pentaacetate & $\mathrm{C}_{28} \mathrm{H}_{24} \mathrm{O}_{15}$ & 600.1117 & 9.996 & $+/-$ & + \\
\hline 9,12,13-Trihydroxy-10,15-octadecadienoic acid & $\mathrm{C}_{18} \mathrm{H}_{32} \mathrm{O}_{5}$ & 328.2253 & 11.398 & - & \\
\hline Punicalin & $\mathrm{C}_{34} \mathrm{H}_{22} \mathrm{O}_{22}$ & 782.0619 & 11.448 & + & \\
\hline Jasmonic acid & $\mathrm{C}_{12}^{34} \mathrm{H}_{18} \mathrm{O} 3$ & 210.1257 & 11.536 & & + \\
\hline Luteolin (isomer 3) & $\mathrm{C}_{15} \mathrm{H}_{10} \mathrm{O}_{6}$ & 286.0484 & 11.864 & $+/-$ & $+/-$ \\
\hline Quercetin & $\mathrm{C}_{15} \mathrm{H}_{10} \mathrm{O}_{7}$ & 302.0434 & 11.91 & - & \\
\hline 4,12-Dihydroxy-hexadecanoic acid & $\mathrm{C}_{16} \mathrm{H}_{32} \mathrm{O}_{4}$ & 288.2306 & 11.913 & - & \\
\hline Methyl-p-coumarate & $\mathrm{C}_{10} \mathrm{H}_{10} \mathrm{O}_{3}$ & 178.0632 & 12.005 & - & \\
\hline 9,12,13-Trihydroxy-10-octadecenoic acid & $\mathrm{C}_{18} \mathrm{H}_{34} \mathrm{O}_{5}$ & 330.2412 & 12.491 & - & \\
\hline Trimethyl ellagic acid (isomer 1) & $\mathrm{C}_{17} \mathrm{H}_{12} \mathrm{O}_{8}$ & 344.0543 & 12.574 & $+/-$ & $+/-$ \\
\hline methyl 9,12-dihydroxy-13-oxo-10-octadecenoate & $\mathrm{C}_{19} \mathrm{H}_{34} \mathrm{O}_{5}$ & 342.2412 & 12.664 & - & \\
\hline Gingerol & $\mathrm{C}_{17} \mathrm{H}_{26} \mathrm{O}_{4}^{3}$ & 294.1837 & 13.015 & - & - \\
\hline Trimethyl ellagic acid (isomer 2) & $\mathrm{C}_{17} \mathrm{H}_{12} \mathrm{O}_{8}$ & 344.0545 & 14.238 & $+/-$ & $+/-$ \\
\hline Trimethyl ellagic acid (isomer 3) & $\mathrm{C}_{17} \mathrm{H}_{12} \mathrm{O}_{8}$ & 344.0545 & 15.116 & $+/-$ & $+/-$ \\
\hline 16-Hydroperoxy-9Z,12,14E-octadecatrienoic acid & $\mathrm{C}_{18} \mathrm{H}_{30} \mathrm{O}_{4}$ & 310.2145 & 15.251 & - & \\
\hline 9,13-Dihydroxy-11-octadecenoic acid & $\mathrm{C}_{18} \mathrm{H}_{34} \mathrm{O}_{4}$ & 314.246 & 20.265 & - & - \\
\hline Heptylheptanoate & $\mathrm{C}_{14} \mathrm{H}_{28} \mathrm{O}_{2}$ & 228.2091 & 20.996 & - & - \\
\hline Palmitic acid & $\mathrm{C}_{16} \mathrm{H}_{32} \mathrm{O}_{2}$ & 256.2413 & 23.869 & - & - \\
\hline
\end{tabular}

+ and - refers to the relevant ionisation mode in which the compound was detected. KLM=Kakadu plum leaf methanolic extract; KLE=Kakadu plum ethyl acetate extract. 


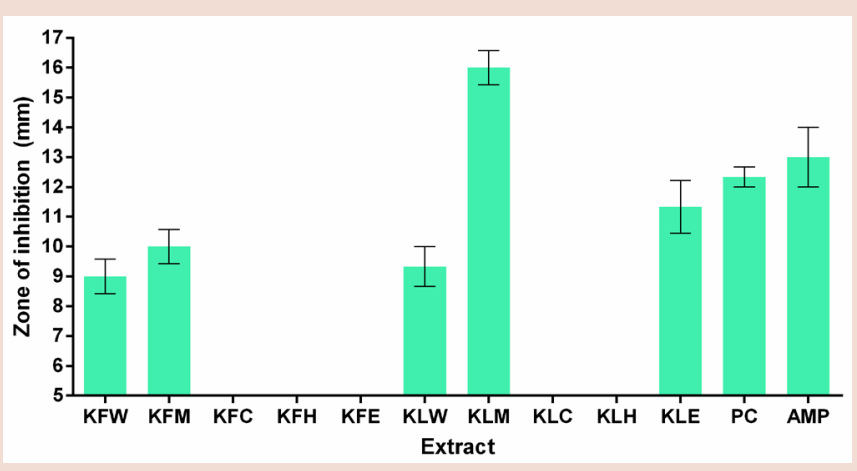

Figure 1: Growth inhibitory activity of Kakadu plum plant extracts against the $C$. perfringens environmental isolate measured as zones of inhibition ( $\mathrm{mm}$ ). KFW=aqueous Kakadu plum fruit extract; $\mathrm{KFM=methanolic}$ Kakadu plum fruit extract; $\mathrm{KFC}=$ chloroform Kakadu plum fruit extract; $\mathrm{KFH}=$ hexane Kakadu plum fruit extract; $\mathrm{KFE}=$ ethyl acetate Kakadu plum fruit extract; $K L W=a q u e o u s ~ K a k a d u$ plum leaf extract; $K L M=$ methanolic Kakadu plum leaf extract; KLC=chloroform Kakadu plum leaf extract; $\mathrm{KLH}=$ hexane Kakadu plum leaf extract; $\mathrm{KLE}=$ ethyl acetate Kakadu plum leaf extract; $\mathrm{PC}=$ penicillin $(2 \mu \mathrm{g})$; $\mathrm{AMP}=$ ampicillin $(10 \mu \mathrm{g})$. Results are expressed as mean zones of inhibition \pm SEM.

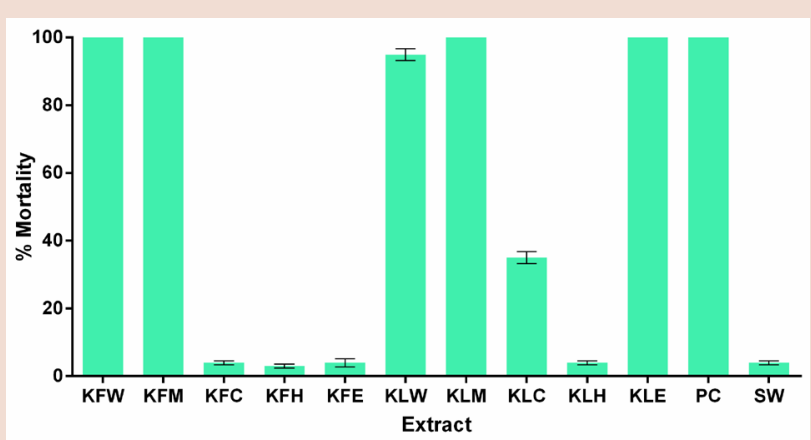

Figure 2: The lethality of the Australian plant extracts $(2000 \mu \mathrm{g} / \mathrm{mL})$ and the potassium dichromate control $(1000 \mu \mathrm{g} / \mathrm{mL})$ towards Artemia franciscana nauplii after $24 \mathrm{~h}$ exposure. $\mathrm{KFW}=$ aqueous Kakadu plum fruit extract; $\mathrm{KFM=methanolic} \mathrm{Kakadu} \mathrm{plum} \mathrm{fruit} \mathrm{extract;} \mathrm{KFC}=$ chloroform Kakadu plum fruit extract; $\mathrm{KFH}=$ hexane Kakadu plum fruit extract; $\mathrm{KFE}=$ ethyl acetate Kakadu plum fruit extract; $\mathrm{KLW}=$ aqueous Kakadu plum leaf extract; $K L M=$ methanolic Kakadu plum leaf extract; $K L C=$ chloroform Kakadu plum leaf extract; $\mathrm{KLH}=$ hexane Kakadu plum leaf extract; $\mathrm{KLE}=$ ethyl acetate Kakadu plum leaf extract; $\mathrm{PC}=$ potassium dichromate control; SW=seawater control. Results are expressed as mean \% mortality \pm SEM.
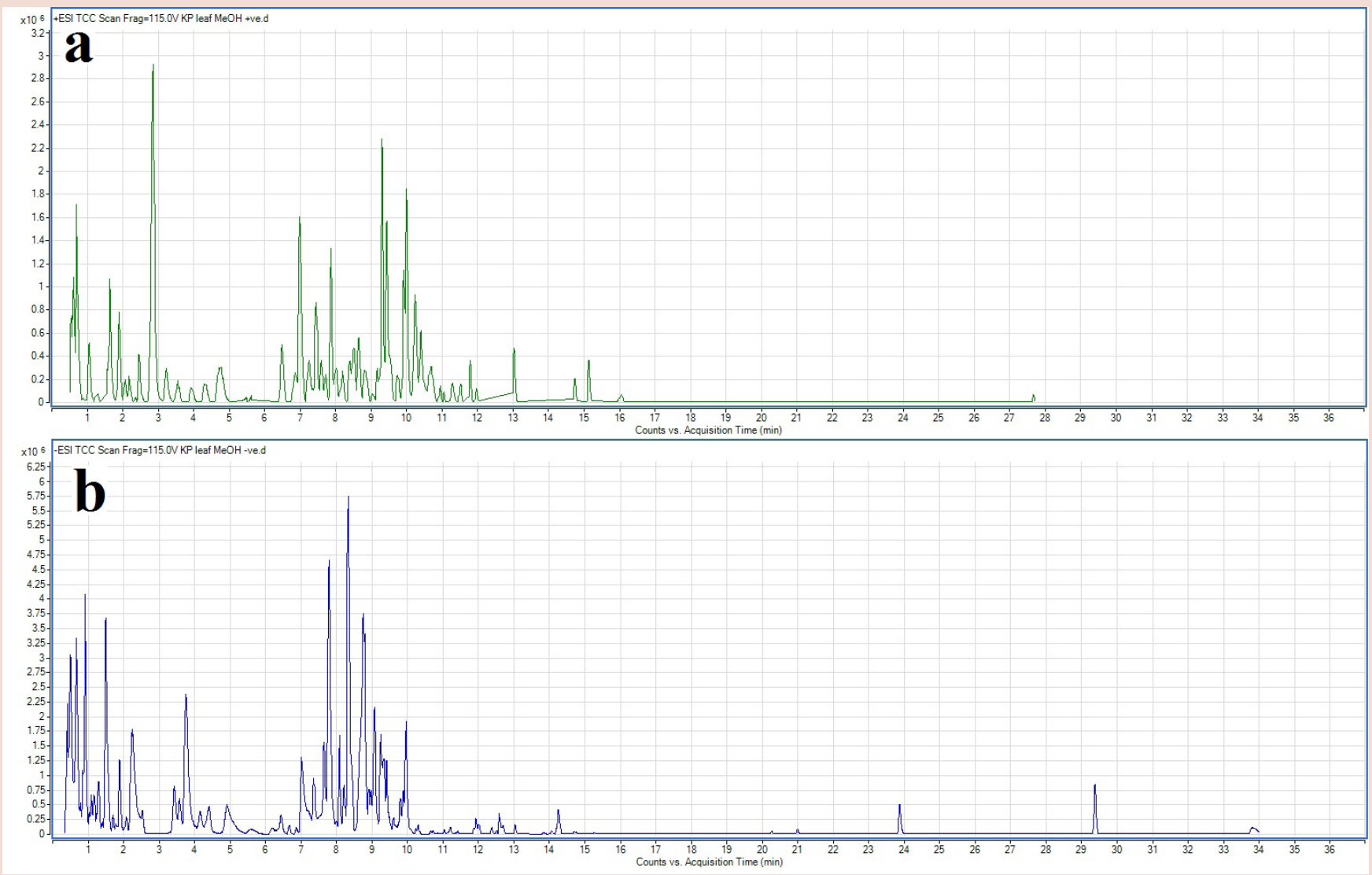

Figure 3: (a) Positive and (b) negative ion RP-HPLC total compound chromatograms (TCC) of $2 \mu$ injections of T. ferdinandiana leaf methanolic extract. 

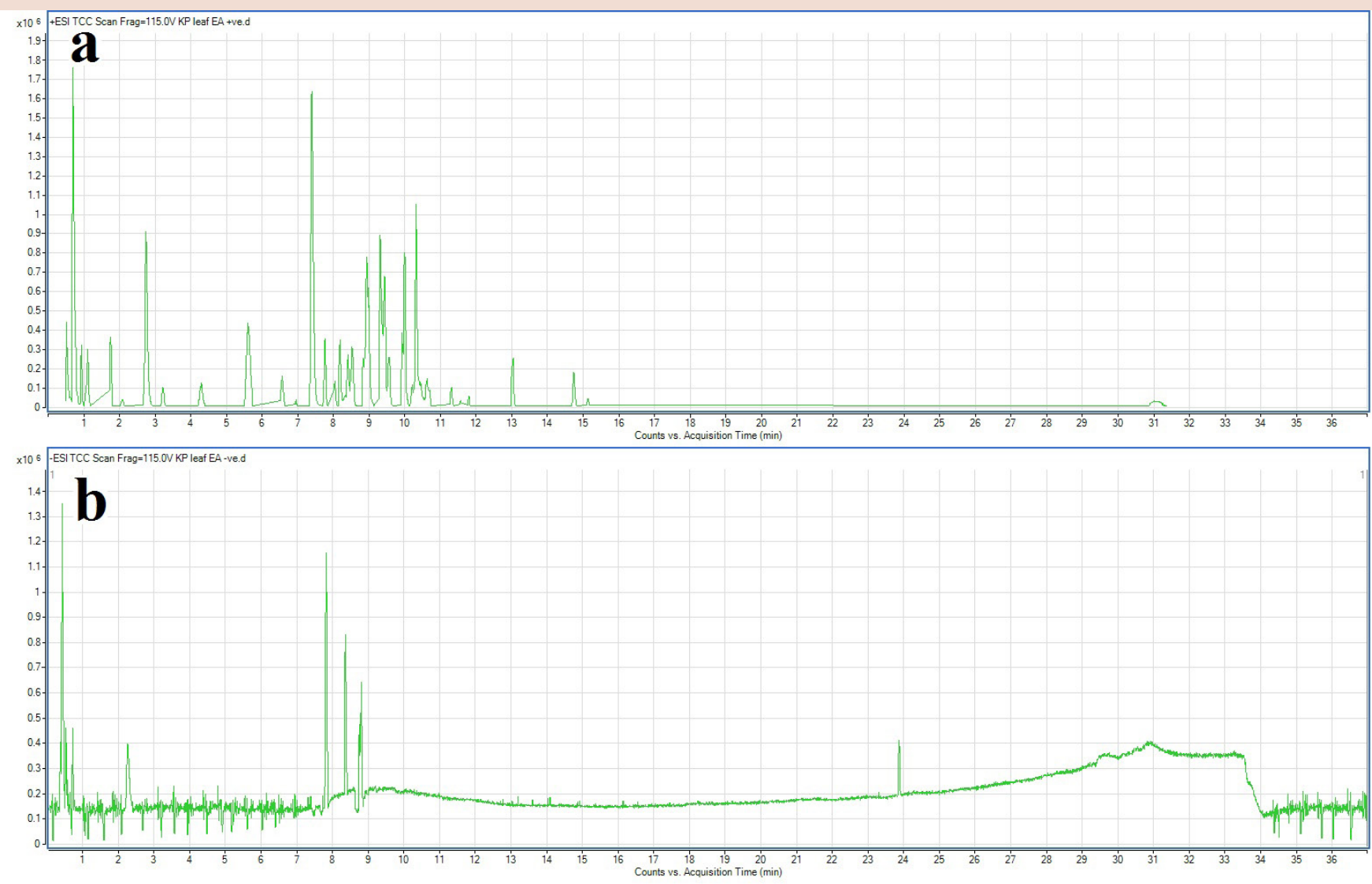

Figure 4: (a) Positive and (b) negative ion RP-HPLC total compound chromatograms (TCC) of $2 \mu$ injections of T. ferdinandiana leaf ethyl acetate extract.

molecular mass signals detected were putatively identified by comparison to the Metlin metabolomics, forensic toxicology (Agilent) and phytochemicals (developed in this laboratory) databases. Seventeen and 8 compounds were detected only in the methanolic and ethyl acetate extracts respectively. The remaining 29 compounds were present in both extracts. The diversity of tannin compounds is noteworthy, with 14 tannin compounds putatively identified across the methanolic and ethyl acetate leaf extracts. In particular, chebulic acid (Figure 5a), protocatechuic acid (Figure 5b), ellagic acid dehydrate (Figure 5c), punicalagin (Figure 5d), ellagic acid (Figure 5e), chebulagic acid (Figure 5f), castalagin (Figure 5g), corilagin (Figure 5h), punicalin (Figure 5i), chebulinic acid (Figure 5j), punicalin (Figure 5k), trimethylellagic acid isomers (Figure $5 \mathrm{l}$ and Figure $5 \mathrm{~m}$ ) were putatively identified.

\section{DISCUSSION}

Previous studies within our laboratory have reported potent growth inhibitory activity for $T$. ferdianadiana fruit extracts against a panel of pathogenic bacterial species. ${ }^{12-5}$ Recently, we also reported growth inhibitory activity of $T$. ferdianadiana fruit ${ }^{13-4}$ and leaf extracts..$^{18}$ against some microbial triggers of selected autoimmune inflammatory diseases. Furthermore, the latter study also screened the phytochemical profile of the bioactive ethyl acetate leaf extract and determined that the extract contained relatively high levels of a number of tannin components including exifone (4-galloylpyrogallol), ellagic acid dehydrate, trimethyl ellagic acid, chebulic acid, corilagen, castalagin, chebulagic acid. Our current study detected a similar tannin profile in the ethyl acetate extract, and also analysed the methanolic leaf extract. The methanolic extract also contained the same tannin compounds, as well as chebulinic acid, ellagic acid, protocatechuic acid, punicalin and punicalagin.

The diversity of ellagitanninsin the methanolic and ethyl acetate T. ferdianadiana leaf extracts was particularly noteworthy. As well as from ellagic acid and the dehydrated and trimethylated derivatives, the more complex, higher molecular weight compounds chebulinic acid and punicalin were also putatively identified and are likely to contribute to the $C$. perfringens growth inhibitory activity of these extracts. Ellagitannins have previously been reported to be potent inhibitors of the growth of a broad panel of bacteria, with MIC values as low as $62.5 \mu \mathrm{g} / \mathrm{ml}^{33-4}$ Ellagitannins have also been reported to function via several antibiotic mechanisms including interaction with cytoplasmic oxidoreductases and by disrupting bacterial cell walls. ${ }^{33-4}$ Gallotannins are also potent bacterial growth inhibitors and have been reported to inhibit the growth of a broad spectrum of bacterial species ${ }^{33}$ through a variety of mechanisms including binding cell surface molecules including lipotoichoic acid and proline-rich cell surface proteins, ${ }^{34-5}$ and by inhibiting glucosyltransferase enzymes. ${ }^{36}$

An important consideration of any metabolomic technique is that it will not detect all compounds in a complex mixture, but instead will only detect a portion of them. This is not necessarily a problem when a directed/biased study is undertaken to detect a particular compound or class of compounds and the separation and detection conditions can be optimised for the study. However, when the aim of the study is metabolomic profiling rather than metabolomic fingerprinting, the technique 


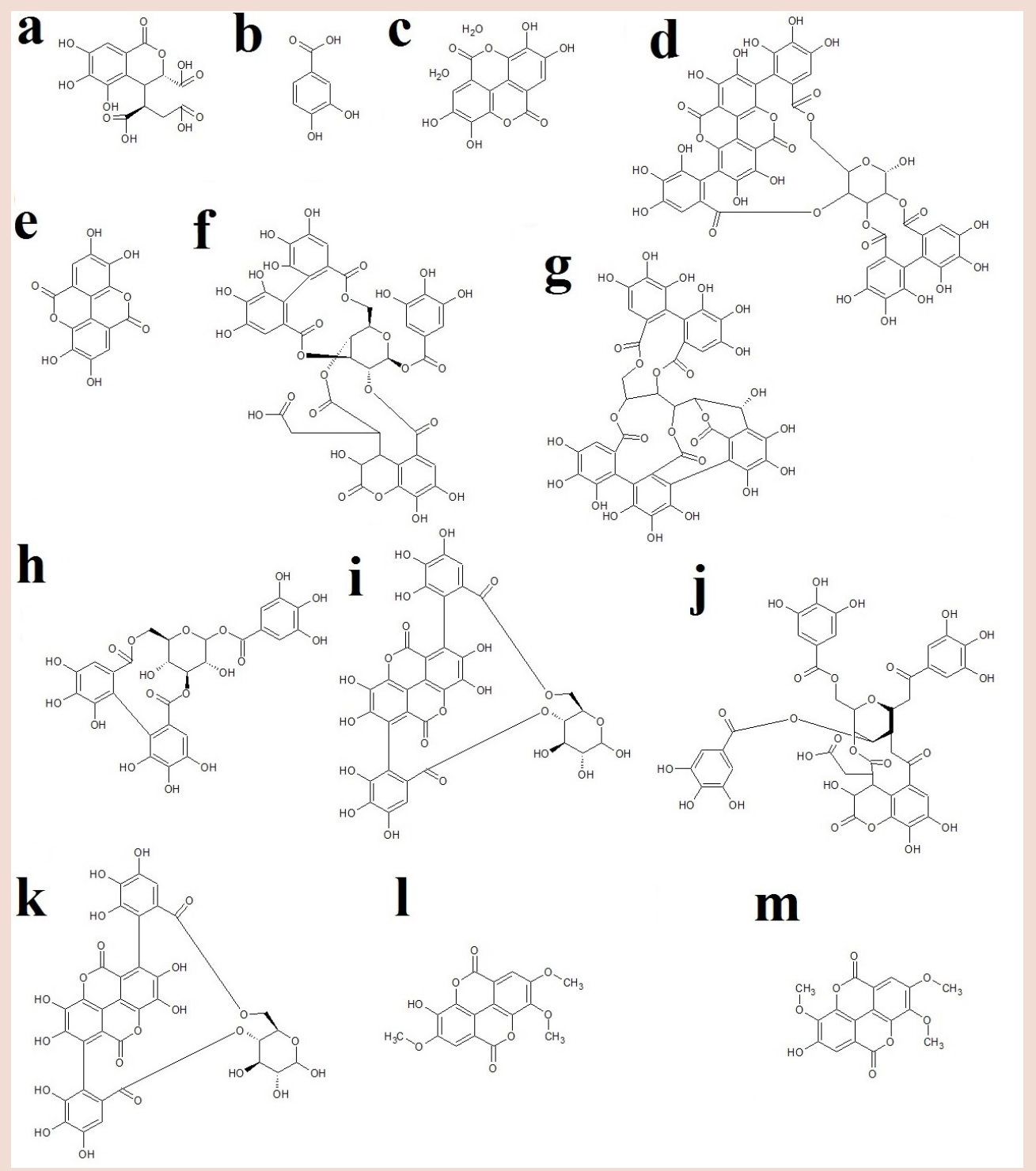

Figure 5: Chemical structures of T. ferdinandiana leaf tannin compounds detected in the methanolic and/or ethyl acetate extracts: (a) chebulic acid; (b) protocatechuic acid; (c) ellagic acid dihydrate; (d) punicalagin; (e) ellagic acid; (f) chebulagic acid; (g) castalagin; (h) corilagin; (i) punicalin; (j) chebulinic acid; (k) punicalin; (I-m) trimethylellagic acid isomers.

conditions must be chosen and optimised to separate and detect the largest amount of compounds, with the broadest possible physical and chemical characteristics. Generally, HPLC-MS is a good choice for such metabolomic profiling studies as it generally detects a larger amount of compounds of varying polarities than the other commonly used techniques. However, this method is limited to studies of the mid-highly polar compounds and is not as useful for studies aimed at highly nonpolar compounds. Thus, many nonpolar phytosterols, saponins, stilbenes and terpenes which may contribute to the inhibitory activity of the leaf extracts may escape detection by HPLC-MS. For this reason, further studies using GC-MS metabolomics analysis are required to detect more of the less polar compounds and provide a more complete picture of the T. ferdianadiana leaf metabolome.

Identification of the less polar compounds was beyond the scope of this study and future studies aimed at identifying these components in the inhibitory leaf extracts are required. Parallel studies have already reported the low polarity compound composition of T. ferdianadiana fruit extracts. ${ }^{13}$ A number of monoterpenoids including isomyocerene, cineole, cuminol, camphor and isomenthol were detected in the ethyl acetate fruit extract. ${ }^{13}$ The amyrin triterpenoid $(3 \beta, 4 \alpha, 16 \alpha, 21 \beta, 22 \alpha)$ olean-12-ene-3,16,21,22,23,28-hexol was also detected by GC-MS in the same study. Many of these terpenoids have been previously reported to have potent broad spectrum antibacterial activity ${ }^{37}$ and therefore may contribute to the growth inhibitory activity against $C$. perfringens if they are subsequently detected in the leaf extracts.

Our studies provide insight into the phytochemical composition of these extracts. However, it is noteworthy that mass spectral techniques alone are generally not capable of differentiating between structural isomers. Further studies using a wider variety of techniques are required to confirm the identity of the compounds putatively identified here. Our 
findings also demonstrated that the T. ferdinandiana extracts display low toxicity towards Artemia franciscana. Indeed, with the exception of the leaf ethyl acetate extract (MIC $767 \mu \mathrm{g} / \mathrm{mL}$ ), the $\mathrm{LC}_{50}$ values for all extracts were well in excess of $1000 \mu \mathrm{g} / \mathrm{mL}$ and are therefore nontoxic. Furthermore, whilst the results of our study are promising, it must be noted that the growth inhibitory studies screened against vegetative cells. As Clostridium spp. are spore formers, further studies are required to determine whether the T. ferdinandiana extracts with $C$. perfringens growth inhibitory activity also affect bacterial growth from the spores.

\section{CONCLUSION}

The results of this study demonstrate the potential of T. ferdianadiana leaf methanolic and ethyl acetate and methanolic fruit extracts to block C. perfringens growth. As these extracts are nontoxic or of low toxicity, they have potential in the prevention and treatment of clostridial myonecrosis and enteritis necroticans. Further studies aimed at the purification and identification of the bioactive components are needed to examine the mechanisms of action of these agents.

\section{ACKNOWLEDGEMENTS}

Financial support for this work was provided by the Environmental Futures Research Institute and the School of Natural Sciences, Griffith University, Australia. The authors are grateful to David Boehme of Wild Harvest, Northern Territory, Australia for providing the T. ferdinandiana leaves and fruit pulp used in these studies.

\section{CONFLICT OF INTEREST}

The authors declare no conflicts of interest.

\section{ABBREVIATION USED}

DMSO: Dimethyl sulfoxide; $\mathbf{I C}_{50}$ : The concentration required to achieve a $50 \%$ reduction of the untreated value; $\mathbf{L C}_{50}$ : The concentration required to achieve 50\% mortality; MIC: Minimum inhibitory concentration.

\section{REFERENCES}

1. Myers GSA, Rasko DA, Cheung JK, et al. Skewed genomic variability in strains of the toxigenic bacterial pathogen, Clostridium perfringens. Genome Research. 2006:16(8):1031-40.

2. Briolat $V$, Reysset G. Identification of the Clostridium perfringens genes involved in the adaptive response to oxidative stress. Journal of Bacteriology. 2002;184(9):2333-43.

3. Huang I-H, Raju D, Paredes-Sabja D, et al. Clostridium perfringens: Sporulation, spore resistance and germination. Bangladesh Journal of Microbiology. 2007; 24(1):1-8.

4. Stevens DL, Bisno AL, Chambers HF, et al. Practice guidelines for the diagnosis and management of skin and soft-tissue infections. Clinical Infectious Diseases. 2005;41(10):1373-406

5. Economedes DM, Santoro J, Deirmengian CA. Clostridium septicum growth from a total knee arthroplasty associated with intestinal malignancy: a case report. BMC Infectious Diseases. 2012;12(1):235.

6. Sheff B. Clostridium perfringens. Nursing. 2004;34(8):31.

7. Aggelidakis J, Lasithiotakis K, Topalidou A. Limb salvage after gas gangrene: a case reportand review of the literature. World Journal of Emergency Surgery. 2011;6:28.

8. Titball, RW. Clostridium perfringens vaccines. Vaccine 2009;27(4):44-7.

9. Khanna N. Clindamycin-resistant Clostridium perfringens cellulitis. Journal of Tissue Viability. 2008;17(3):95-7.

10. Cock IE. The medicinal properties and phytochemistry of plants of the genus Terminalia (Combretaceae). Inflammopharmacology. 2015;23(5):203-29. DOI 10.1007/s10787-015-0246-z

11. Mohanty S, Cock IE. The chemotherapeutic potential of Terminalia ferdinandiana: Phytochemistry and bioactivity. Pharmacognosy Reviews. 2012;6(11):29-36. DOI: 10.4103/0973-7847.95855

12. Wright MH, Sirdaarta J, White A, et al. GC-MS headspace analysis of Terminalia ferdinandiana fruit and leaf extracts which inhibit Bacillus anthracis growth. Pharmacognosy Research. 2016; in press.
13. Sirdaarta J, Matthews B, White A, et al. GC-MS and LC-MS analysis of Kakadu plum fruit extracts displaying inhibitory activity against microbial triggers of multiple sclerosis. Pharmacognosy Communications. 2015;5(2):100-15. DOI: 10.5530/pc.2015.2.2

14. Sirdaarta J, Matthews B, Cock IE. Kakadu plum fruit extracts inhibit growth of the bacterial triggers of rheumatoid arthritis: Identification of stilbene and tannin components. Journal of Functional Foods. 2015;17:610-20. DOI: 10.1016/j. jff.2015.06.019

15. Cock IE, Mohanty S. Evaluation of the antibacterial activity and toxicity or Terminalia ferdinandiana fruit extracts. Pharmacognosy Journal. 2011;3(20):72 9. DOI: 10.5530/pj.2011.20.14

16. Cock IE. Medicinal and aromatic plants-Australia. In Ethnopharmacology, Encyclopedia of Life Support Systems (EOLSS) 2011. Developed under the auspices of UNESCO. Oxford UK; EOLSS Publishers; 2011.

17. Lassak EV, McCarthy TM. Australian medicinal plants. A complete guide to identification and usage. New Holland Publishers 2011; Sydney, Australia.

18. Courtney R, Sirdaarta J, Matthews B, et al. Tannin components and inhibitory activity of Kakadu plum leaf extracts against microbial triggers of autoimmune inflammatory diseases. Pharmacognosy Journal. 2015;7(1):18-31. DOI: 10.5530/pj.2015.7.2

19. Arkhipov A, Sirdaarta J, Rayan $P$, et al. An examination of the antibacterial, antifungal, anti-Giardial and anticancer properties of Kigelia africana fruit extracts. Pharmacognosy Communications. 2014;4(3):62-76. DOI: 10.5530/pc.2014.3.7

20. Kalt FR, Cock IE. Gas chromatography-mass spectroscopy analysis of bioactive Petalostigma extracts: Toxicity, antibacterial and antiviral activities. Pharmacognosy Magazine. 2014;10(37 Suppl):S37-49. DOI: 10.4103/0973-1296.127338

21. Rayan $P$, Matthews $B, M c D o n n e l l ~ P A$, et al. Terminalia ferdinandiana extracts as inhibitors of Giardia duodenalis proliferation: a new treatment for giardiasis. Parasitology Research. 2015;114(7):2611-20. DOI 10.1007/s00436-015-4465-4

22. Jamieson N, Sirdaarta J, Cock IE. The anti-proliferative properties of Australian plants with high antioxidant capacities against cancer cell lines. Pharmacognosy Communications. 2014;4(4):71-82. DOI: 10.5530/pc.2014.4.8

23. Winnett $\mathrm{V}$, Boyer $\mathrm{H}$, Sirdaarta J, et al. The potential of Tasmannialanceolata as a natural preservative and medicinal agent: antimicrobial activity and toxicity. Pharmacognosy Communications. 2014;4(1):42-52. DOI: 10.5530/pc.2014.1.7

24. Cock IE. Antimicrobial activity of Syzygium australe and Syzygium leuhmannii leaf menthanolic extracts. Pharmacognosy Communications. 2012;2(2):71-7. DOI: $10.5530 /$ pc.2012.2.11

25. Wright $\mathrm{MH}$, Matthews $\mathrm{B}$, Greene $\mathrm{AC}$ et al. Growth inhibition of the zoonotic bacteria Bacillus anthracis by high antioxidant Australian plants: New leads for the prevention and treatment of anthrax. Pharmacognosy Communications. 2015;5(3):173-89. DOI: 10.5530/pc.2015.3.3

26. Sautron C, Cock IE. Antimicrobial activity and toxicity of Syzygium australe and Syzygium leuhmannii fruit extracts. Pharmacognosy Communications. 2014;4(1):53-60. DOI: 10.5530/pc.2014.1.8

27. Vesoul J, Cock IE. The potential of Bunya nut extracts as antibacterial functional food agents. Pharmacognosy Communications. 2012;2(1):72-9. DOI: 10.5530/ pc.2012.1.13

28. Cock IE, van Vuuren SF. Anti-Proteus activity of some South African medicinal plants: their potential for the prevention of rheumatoid arthritis. Inflammophar macology. 2014;22(1):23-36. DOI 10.1007/s10787-013-0179-3

29. Cock IE. Antimicrobial activity of Acacia aulacocarpa and Acacia complantamenthanolic extracts. Pharmacognosy Communications. 2012;2(1):66-71. DOI: 10.5530/pc.2012.1.12

30. Ruebhart D, Wickramasinghe W, Cock IE. Protective efficacy of the antioxidants vitamin $\mathrm{E}$ and Trolox against Microcystis aeruginosa, microcystin-LR and menadione toxicity in Artemia franciscana nauplii. Journal of Toxicology and Environmental Health Part A. 2009:72(24):1567-75. DOI: 10.1080/15287390903232459

31. Cock IE, Winnett V, Sirdaarta J, et al. The potential of selected Australian medicina plants with anti-Proteus activity for the treatment and prevention of rheumatoid arthritis. Pharmacognosy Magazine. 2015;11(42 Suppl):S190-208. DOI: 10.4103/0973-1296.157734

32. Cock IE, Ruebhart DR. Comparison of the brine shrimp nauplii bioassay and the ToxScreen-II test for the detection of toxicity associated with Aloe vera (Aloe barbadensis Miller) leaf extract. Pharmacognosy Research. 2009;1(2):98-101.

33. Buzzini P, Arapitsas P, Goretti M, et al. Antimicrobial activity of hydrolysable tannins. Mini-Reviews in Medicinal Chemistry. 2008;8(12):1179-87.

34. Hogg SD, Embery G. Blood-group-reactive glycoprotein from human saliva interacts with lipoteichoic acid on the surface of Streptococcus sanguis cells. Archives in Oral Biology. 1982;27(3):261-8.

35. Wolinsky LE, Sote EO. Isolation of natural plaque-inhibiting substances from 'Nigerian chewing sticks'. Caries Research. 1984;18(3):216-25.

36. Wu-Yuan CD, Chen CY, Wu RT. Gallotannins inhibit growth, water-soluble glucan synthesis, and aggregation of Streptococci mutans. Journal of Dental Research. 1988;67(1):51-5.

37. Cock IE. The phytochemistry and chemotherapeutic potential of Tasmania lanceolata (Tasmanian pepper): A review. Pharmacognosy Communications. 2013:3(4):1-13. 
PICTORIAL ABSTRACT

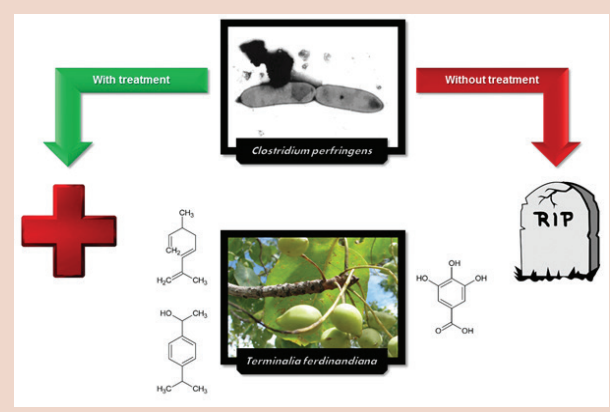

\section{SUMMARY}

- T. ferdinandiana fruit and leaf extracts were inhibitors of Clostridium perfringens growth.

- Methanolic and ethyl acetate leaf extracts were particularly potent growth inhibitors, with MIC's of 206 and $117 \mu \mathrm{g} / \mathrm{ml} \mu \mathrm{g} / \mathrm{mL}$ respectively.

- All inhibitory extracts were non-toxic in the Artemia nauplii assay.

- LC-MS metabolomic profiling of the inhibitory extracts highlighted a diversity of tannin compounds in the inhibitory leaf extracts.

\section{ABOUT AUTHORS}
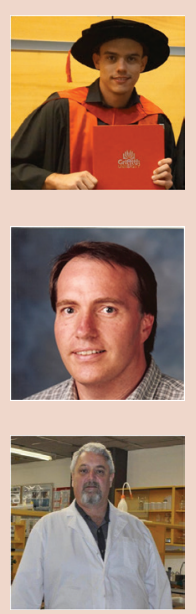

Dr Mitchell Wright: Received his PhD in 2014, for his work investigating the manganese reduction and oxidation characteristics of environmental bacteria. He is currently a postdoctoral researcher at Griffith University, Australia, where he is working on several projects both in the areas of geomicrobiology and pharmocognosy. His present research interests are the use of biogenic manganese oxides in the bioremediation of metalcontaminated sites as well as the use of Australian native plants in the treatment and prevention of various pathogenic bacteria.

Dr Anthony Greene: Is a senior lecturer and researcher at Griffith University, Brisbane Australia. He obtained his $\mathrm{PhD}$ in Microbiology from the University of New South Wales and focuses on extreme environments, bioremediation and geomicrobiology. His specific interests include the microbial ecology of thermophilic, saline and alkaliphilic environments and the mechanisms and industrial potential of extremophilic bacteria contained therein.

Dr lan Cock: Leads a research team in the Environmental Futures Research Institute and the School of Natural Sciences at Griffith University, Australia. His research involves bioactivity and phytochemical studies into a variety of plant species of both Australian and international origin, including Aloe vera, South Asian and South American tropical fruits, as well as Australia plants including Scaevola spinescens, Pittosporum phylliraeoides, Terminalia ferdinandiana (Kakadu plum), Australian Acacias, Syzygiums, Petalostigmas and Xanthorrhoea johnsonii (grass trees). This range of projects has resulted in nearly 200 publications in a variety of peer reviewed journals. 